\title{
Effect of Cement Kiln Dust on unconfined compressive strength property of expansive soil
}

\author{
Suli Cui ${ }^{\mathrm{a}}$, Yanfeng Du ${ }^{\mathrm{b}}$, Mingjin $\operatorname{Tian}^{\mathrm{c}}$ and Xuepan Wang ${ }^{\mathrm{d}}$ \\ State Key Laboratory of Continental Dynamics, Geological Department of Northwest University, \\ Xi'an, Shanxi 710069, China) \\ acuisl@nwu.edu.cn, bdy@nwu.edu.cn, ${ }^{\text {ctmm@nwu.edu.cn, }{ }^{d} w x @ n w u . e d u . c n ~}$
}

\begin{abstract}
Keywords: Cement Kiln Dust (CKD); expansive soil; unconfined compressive strength; curing ages Abstract. In this paper, expansive soil is mixed with CKD in different proportions, and unconfined compressive strength test was conducted on the specimens with a certain initial water content and dry density. Unconfined compressive strength test were also conducted for specimens maintained for different curing ages separately, with $10 \%$ CKD content ratio, to investigate the effect of both CKD content ratio and curing age on the strength property. It was shown that with the increase of CKD content ratios, unconfined compressive strength was first increased, and then decreased. With the growth of the curing age, unconfined compressive strength of the specimen increased exponentially, tending towards stability after about 28 days.
\end{abstract}

\section{Introduction}

Expansive soils are a kind of soils that have significant swelling and shrinkage properties under changing water content, and have been detected in many parts of the world, such as Canada, China, South Africa, Jordan, Australia, the United States and so on. The clay composition is mainly composed of hydrophilic mineral of montmorillonite and illite. Because of the swelling pressure or contraction crack produced by absorbing or losing water, the harm expansive soil in engineering construction is repeatability, long-term and potential[1]. How to reduce the swell-shrink characteristics of expansive soil has long been a common global research topic [2,3].

Lounghnam[4], Grime[5] and Yueqing Hao [6] have given an explanation of expansion mechanism according to the composition of expansive soil from the mineralogical, physical and chemical mechanism. Delage and Graham [7], Alonso[8], Shi Bin[9] based on the research of the microstructure, indicated that chemical and physical properties of expansive soil and water properties mainly depends on the composition of soil, and swell-shrink property, strength and deformation characteristic depends on the structure characteristics of the expansive soil. Lime [10] and cement [11] are ones of the most common and successful soil stabilizers. However, the cost of modification by these two kinds is higher. In order to reduce the cost, fly ash [12], Gypsum Waste Plasterboard [13] and fibers [14] have been used as modified materials by some researchers. Using industrial waste to improve soil properties not only reduce the material consumption, but also solve the problem caused by industrial waste.

Cement Kiln Dust(CKD), which is mixture of airborne particles of cement raw materials, is a potentially valuable materials for stabilizing soils[15]. Baghdadi [16] indicated that CKD has a significant influence on the hydro-physical for a highly plastic bentonite (sodium montmorillonite). The plasticity index (PI) was $326 \%$ with $8 \%$ CKD content ratio, while the value was $513 \%$ for untreated bentonite. The same result was also obtained by Zaman et al[17]. Both Zaman et al. and Baghdadi et al[18] found that with the increase of CKD content ratio and curing periods, the unconfined compressive strength exhibited an increase. In this paper, the authors focused on investigations of the effectiveness of CKD produced in China as soil stabilizers for expansive soil located in Western China. Different proportions of CKD content were added to expansive soil, and unconfined compressive strength tests were conducted on mixtures of expansive soil-CKD. 


\section{Materials and procedure}

\section{Materials}

Expansive soil used in this investigation was obtained from the City of Ankang in Shanxi province in China. It is Brown silty clay, and was selected at a depth of about $1.5-2.0 \mathrm{~m}$. A field density test was carried out, and the disturbed soil was excavated, placed in plastic bags and transported to the Laboratory for preparation and testing. The plasticity index is 40.41 , according to the method recommended in GBJ112-87Standard for construction technical of expansive soil region (in PRC), this soil belongs to weak expansive soil. The indexes for physical characteristics of expansive soils were shown in Table 1.

Table 1 Indexes for physical characteristics of expansive soils

\begin{tabular}{|c|c|c|c|c|c|c|c|c|c|}
\hline Indexes & $\begin{array}{c}\text { Natural } \\
\text { water } \\
\text { content } \\
1 \%\end{array}$ & LL/\% & PL/\% & $\begin{array}{c}\text { Free } \\
\text { swell } \\
\text { ratio/\% }\end{array}$ & $\begin{array}{c}\text { Relative } \\
\text { density }\end{array}$ & $\begin{array}{c}<0.003 \mathrm{~m} \\
\mathrm{~m}\end{array}$ & $\begin{array}{c}<0.005 \mathrm{~m} \\
\mathrm{~m}\end{array}$ & $\begin{array}{c}0.005 \mathrm{~mm} \\
-0.075 \mathrm{~m} \\
\mathrm{~m}\end{array}$ & $\begin{array}{c}>0.075 \mathrm{~m} \\
\mathrm{~m}\end{array}$ \\
\hline $\begin{array}{c}\text { Expansiv } \\
\text { e soil }\end{array}$ & 6.15 & 57.78 & 17.37 & 52 & 2.76 & 10.08 & 35.21 & 39.28 & 25.51 \\
\hline CKD & 0.60 & - & - & - & 2.61 & 70.33 & 80.35 & 12.45 & 7.20 \\
\hline
\end{tabular}

The cement kin dust (CKD) was supplied by a JingYang cement company in Shanxi province in China. It is off white thinner powder. The cement kin dust (CKD) was supplied by a Jing Yang cement company in Shanxi province in China. It is offwhite thinner powder. The indexes for physical characteristics of cement kin dust were shown in Table 1.

\section{Experimental procedure}

Laboratory tests are according to the JTJ051-93 Standard for Road soil test (in PRC). CKD content ratio $\left(R_{\mathrm{c}}\right)$ is defined as the dry mass of CKD to the dry mass of the expansive soil-CKD mixtures. To prepare swell test specimens, CKD was added to expansive soil with different $R_{\mathrm{c}}$ and was initially mixed with a spoon. Then distilled water was added to the mixtures with water content of $22 \%$, and then the soils were mixed carefully by hand until a uniform mixture was obtained. The mixtures were placed in plastic bags and sealed to avoid the loss of water, and allowed to cure in a humidor for $24 \mathrm{~h}$. Compacted tests were conducted by JDS-2 standard compaction apparatus. Strength tests were prepared by statically compacting in a confining ring, the initial dry density for all the specimens were $1.68 \mathrm{~g} / \mathrm{cm}^{3}$ with $22 \%$ water content according to the maximum dry density and optimum water content for expansive soil. And then specimens were cut by the standard cutting ring ( $\mathrm{H}=20 \mathrm{~mm}, \Phi=61.8 \mathrm{~mm})$ for later tests.

In addition, in order to study the effect of curing ages on the shear strength, tests were conducted on specimens with curing ages of 1,7,14 and 28 days.

\section{Results and discussion}

\section{Effect of CKD on unconfined compressive strength}

Unconfined compressive strength tests were conducted and the relationship between axial stress and axial strain were shown in Fig. 1. Results indicated that, with the increase of CKD content ratio, the curves of axial stress-axial strain change by the stress-strain softening to the stress-strain softening hardening obviously, but there was also a peak value. Specifically, when the CKD content was lower $\left(R_{\mathrm{c}}=0 \%, 2 \%\right)$, with the increase of axial displacement, the axial stress was first increased to peak value, then decreased, and drop significantly; When the CKD content ratio was in a higher level $\left(R_{\mathrm{c}}=8 \%\right.$, $10 \%$ ), with the increase of axial displacement, the axial stress was increased to the peak value gradually, and then decreased, but the drop was inconspicuous. 


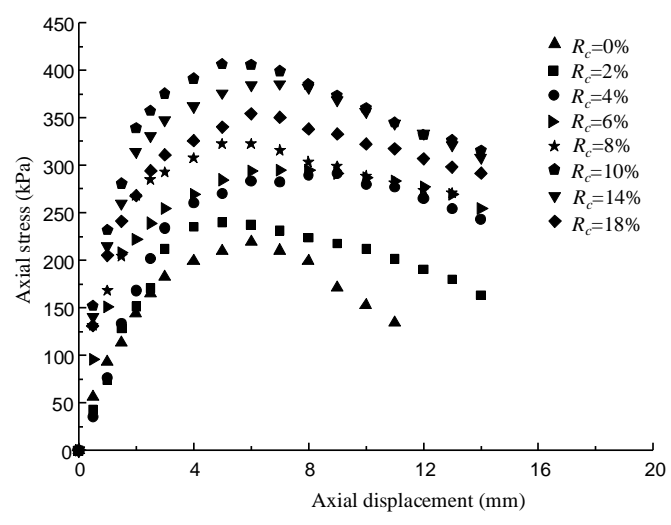

Fig.1 Axial stress vs. axial strain

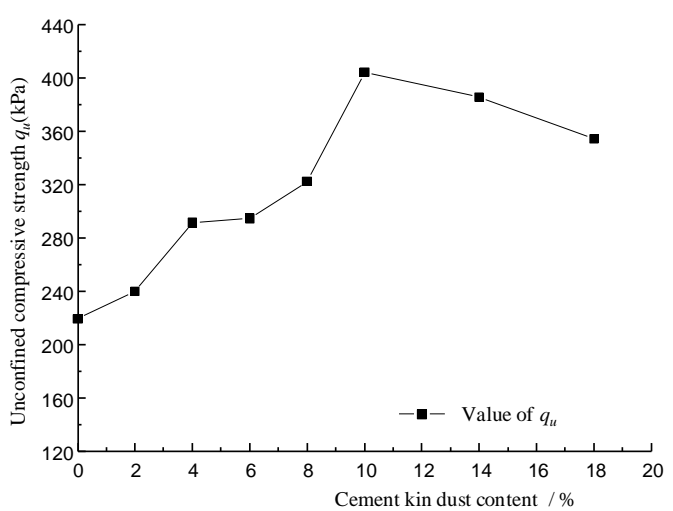

Fig. 2 Unconfined compressive strength vs. CKD content ratio

The changes of unconfined compressive strength with the increase of CKD are shown in Fig.2. It can be seen that with the increase of CKD content ratios, the value of the unconfined compressive strength first increases then decreases. The maximum value is $404 \mathrm{kPa}$ for mixtures with $10 \%$ content ratio, when the CKD content increased to $14 \%$ and $18 \%$, the value decreased to $385.54 \mathrm{kPa}$ and $354.26 \mathrm{kPa}$, but these values were also higher than that of mixtures with $10 \%$ content ratio.

According to the results above, it can be seen that with the increase of CKD content ratio, the unconfined compressive strength of CKD treated expansive soil presented a trend which was first improved then declined. A critical CKD content ratio was appeared. There were two opposite effects of CKD when it was added to expansive soil, the effective one was making the particles together, including ion-exchange adsorption between CKD and expansive soil, pozzolanic reaction and carbonation reaction. pozzolanic reaction generates aqueous calcium silicate and carbonate reaction Generates solid $\mathrm{CaCO}_{3}$, these reactions are the determinant for improving the early and late strength of modified soil. However, for there is a part of CKD which do not take part in reaction, it will weaken the bond between soil particles. When the CKD content ratio is lower, the coupling effect produced by CKD exceeds the weaken effect, the strength increase with the increase of CKD content; When the content reaches a critical, with the increase of CKD content, the weaken effect will exceed the coupling effect, the strength will be decreased, this is why the value of strength were first increased then reduced. However, the effect of the latter was less than that of the former one.

\section{Effect of curing age on unconfined compressive strength}

To check the effect of curing ages on the strength properties of expansive soil-CKD mixtures,mixtures with $10 \%$ content were chosen according to the result above. Specimens were maintained for $1 \mathrm{~d}, 7 \mathrm{~d}$, $14 \mathrm{~d}$ and $28 \mathrm{~d}$ and then unconfined compressive strength tests were conducted. Fig. 3 shows that with the increase of curing ages the curves of axial stress-axial strain changed a little, although with the increase of CKD content, the peak value became more apparent.

Figure 4 provided the relationship between unconfined compressive strength and curing age. The value of the unconfined compressive strength increased exponentially with the curing period, the regression equation is as follows:

$$
q_{u}=-151.18 * \exp (-\mathrm{t} / 7.8746)+487.39 ; R_{2}=1
$$

From the curve and the regression equation, it can be inferred that the strength of the specimen was tended to steady, even if the curing period continues to increase, the value of the unconfined compressive strength will not change significantly with the curing increase.

The cementation of $\mathrm{CaCO} 3$ will form the stabilized soil; the process is quite long, formed the later strength of treated soil. At the same time, during the late ion exchange reaction, hydrogenous $\mathrm{CaSiO} 3$, $\mathrm{CaO}$ and $\mathrm{Al} 2 \mathrm{O} 3$ will be formed along with the curing age increase which because silicon and aluminum in expansive soil will make further reaction. These two kinds of gel can become hardening in a water environment, and this will form a stable outer protective film on the outside of the expansive soil clay, forming a mesh structure and making soil to have a strong cohesive force, this also will increase the later strength of treated expansive soil. 


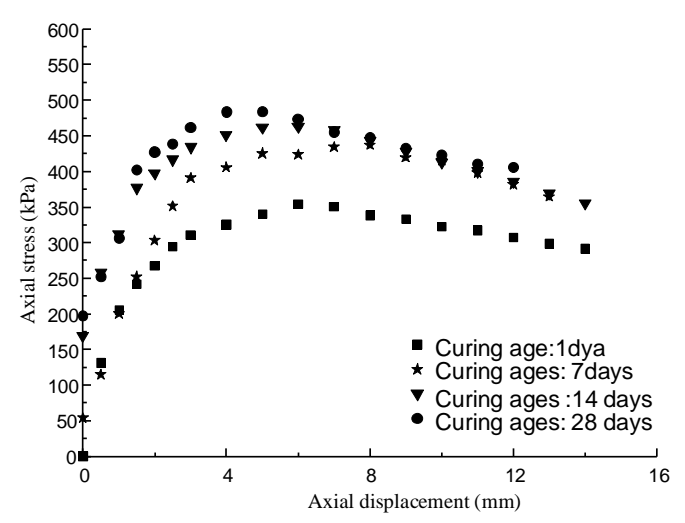

Fig.3 Axial stress vs. axial strain

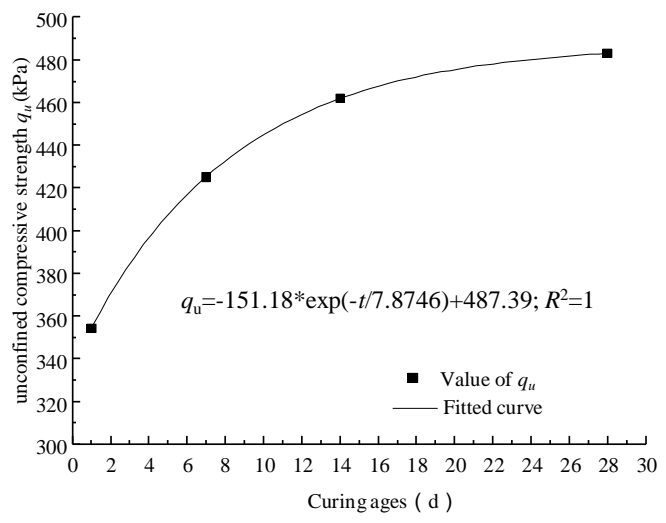

Fig.4 Unconfined compressive strength vs. curing ages

From the curve and the regression equation, it can be inferred that the strength of the specimen was tended to steady, even if the curing period continues to increase, the value of the unconfined compressive strength will not change significantly with the curing increase.

The cementation of $\mathrm{CaCO}_{3}$ will form the stabilized soil; the process is quite long, formed the later strength of treated soil. At the same time, during the late ion exchange reaction, hydrogenous $\mathrm{CaSiO}_{3}$, $\mathrm{CaO}$ and $\mathrm{Al}_{2} \mathrm{O}_{3}$ will be formed along with the curing age increase which because silicon and aluminum in expansive soil will make further reaction. These two kinds of gel can become hardening in a water environment, and this will form a stable outer protective film on the outside of the expansive soil clay, forming a mesh structure and making soil to have a strong cohesive force, this also will increase the later strength of treated expansive soil.

\section{Conclusion}

This paper has made unconfined compressive strength tests of expansive soil with different CKD content ratios and curing ages, the following conclusions can be derived:

(1) The unconfined compressive strength was not change monotonously with the increase of CKD content ratio, there was a critical value which is about $10 \%$. When the CKD content was lower than this value, the value of $q_{u}$ was increase with its increase, while it decreased after this value.

(2) Curing age also has effect on the unconfined compressive strength. With the increase of curing ages, the value of $q_{u}$ was increased exponentially, and the value will keeps unchanged after 28 curing age.

(3) For expansive soil treated with CKD, the optimum mixing CKD content rate is $10 \%$, and the suggested curing age is 28 days.

\section{Acknowledgements}

This work was financially supported by the National Natural Science Foundation of China (No.41402260) and Ph.D. Programs Foundation of Ministry of Education of China (20136101120006). Sincere thanks to the reviewers for their time and courtesy, for assisting the authors to maintain the quality of the paper.

\section{References}

[1] S.L. Li. Research of expansive soil engineering geological in China. Nanjing: Jiangsu Science and Technology Publishing House, (1992).

[2] H.E. Woeley. Methods used in Kansas to Assistant Highway Engineer, State Highway Commission, Kansas, Nov.(1959).

[3] H.B. Seed, R.J.Jr. Woodward and R. Lundgren. Prediction of Swelling Potential for compacted clays, jourma; pf the soil mechanics and foundations division, ASCE, Vol 88, NoSM3. proc,paper 3169, 
June. (1962), 53-87.

[4] F.C. Lounghnam. Chemical weathering of the silicate minertls. M. Eleseviver, New York, (1969).

[5] R.E. Grime. Clay mineralogy [M]. Mcgraw Hill, New York (and Edutuib),(1986).

[6] Y.Q. Hao and J.Q. Zhu. Theories and Analysis About Expensive Soil Deformation of Swelling and Shrinking. Bulletin of soil and water conservation, (1999), 19(6): 58-61.

[7] P. Delage, and J. Graham. Mechanical behavior of unsaturated soils: Understanding the behaviour of unsaturated soils require reliable conceptual models. Proc. 1st int. conf. Unsaturated soil, (1995), Paris.

[8] E.E. Alonso, A. Gens and A. Josa. A constitutive model for patially saturated soils. Geotechnique, (1996), 40(3): 405-430.

[9] B. Shi, S.L. Li and M.Tolkachev. Study of clayey soil microstructur quantificationally with SEM image. Science in china (Series A), (1995), 25(6):666-672.

[10] S.L. Sun and F. Li. Electrical resistivity measurement for lime-stabilized silt soil. Rock and Soil Mechanics, 2010, 31(1): 51-55.

[11] D.O.A. Osula. A comparative evaluation of cement and lime modification of laterite.,Engineering Geology, (1996), 42(4): 71-78.

[12] N. N. Khoury and M. M. Zaman. Effects of wet-dry cycles on resilient modulus of class C fly ash stabilized aggregate base. Transportation Research Record. 1787, Transportation Research Board, National Research Council, Washington, D.C. (2002).

[13] A. Ahmed, K. Ugai and T. Kamei, Environmental Evaluation for Clayey Soil Stabilized with Gypsum Waste Plasterboard in Japan. J. Geotechnical Special Publication No. 217, ASCE. (2011).

[14] Abd El Megeed Kabasy Mohamed, Improvement of swelling clay properties using hay fibers. Construction and Building Materials 38, (2013), 242-247.

[15] G.A. Miller and S. Azad. Influence of soil type on stabilization with cement kiln dust, Construction and Building Materials. (2000), 14(2): 89-97.

[16] Z.A. Baghdadi. Utilization of kiln dust in clay stabilization. King Abdulaziz Univ.: Eng Sci. (1990), 2, 53-163.

[17] M. Zaman, J.G. Laguros and A.I. Sayah. Soil stabilization using cement kilndust. Proceeding of the 7th International Conference on Expansive Soils, Dallas, TX, (1992), 1-5.

[18] Z. A. Baghdadi, M. N. Fatani and N. A. Sabban. "Soil modification by cement kiln dust." Mater. Civ. Eng., (1995). 7(4), 218-222. 